\title{
Some Points to Ponder on Some Biotechnologies of Current \& Future Relevance
}

\author{
Adhikarla S Rao* \\ Department of Biotechnology, Bharathidasan University, India
}

Submission: March 03, 2017; Published: May 04, 2017

*Corresponding author: Adhikarla S Rao, Department of Biotechnology, Bharathidasan University, Tiruchirappalli-620024, Tamil Nadu, India, Email: adhikarla@gmail.com

\section{Genetically Modified Plants/Crops (Gentically Engineered Plants/Crops)}

Genetic engineering technology is used to develop several crops for resistance to biotic and abiotic stresses, producing drugs and vaccines (Pharmaceuticals and edible vaccines), expression of useful recombinant proteins, increased nutrient value (nutriceuticals particularly bio fortification of micronutrients which impact human health) tailoring crops for industrial applications, prolonging the shelf life of products, increasing the aesthetic value of products, etc

Many GM crops in Cotton, Maize, Potato, Rape Seed, Soybean, Sugar Beet, Carnations, Rice, etc are approved and are awaiting approval. Mostly they are for herbicide resistance, insect resistance, altered composition, altered flower colors, drought tolerance, male sterility, Only few Multinational companies are mostly involved in this endeavor Viz; Monsanto, Syngenta, Bayer Crop science, Dow Agro Science, Mycogen seeds, Florigene. Pioneer Hi-bred International, BASF Plant science and KWS Saat AG. In addition to Multinational companies different countries also are involved in developing different GM crops. In many of the above crops it has been shown that farmers have to rely on less pesticides and herbicides decreasing the cost of cultivation and increasing the yields and there by reaping more profits. However data varies across various parameters.

A recent venture is scientists trying to convert C3 crops into C4 crops e.g. rice. In this process scientists are predicting the lowering of amounts of Rubisco (Ribulose 1, 5 bis phosphate carboxylase-oxygenase) in leaves..A concern here is, Rubisco also acts as a storage protein during grain development. It may contribute up to $50 \%$ to the soluble leaf proteins and 20-30 $\%$ of total leaf nitrogen in C3 leaves. During grain development Rubisco is degraded into amino acids and supplied to the developing grains. If the amount of Rubisco is lowered, it may eventually effect grain development, protein concentration and yield. Presently scientists are either indifferent or secretive about the goal. I speculated one strategy to mitigate the above mentioned fears/concern. Better clone the necessary C-4 genes into C-3 chloroplasts without the need for creating Kranz anatomy. All the enzymes of C-4 photosynthesis already exist in C-3 plants and field of chloroplast engineering is now getting more and more advanced. However even the scientists who are presently working in different directions are not clear as to which type of C-4 plant is going to arise as a result of genetic engineering- NADP-ME or NAD-ME or PEPCK ? (ME=Malic enzyme; PEPCK= phosphoenolpyruvate carboxykinase).

In the present year 2017, three new potato varieties Viz; the Russet Burbank, Ranger Russet and Atlantic were approved by the U.S. Environmental Protection Agency and Food and Drug Administration. These varieties possess multiple advantages Viz; resistance to late blight disease, better shelf life, drastic reduction in the need for fungicides, safer to cook at high temperatures. With all these merits they possess the same taste, texture and nutritional characteristics. Presently the debate on GM crops is still very active, emotional and controversial. (An important point to be noted is, USA etc accepting them does not mean that the farmers are growing only GM crops. The acreage under GM crops is in fact a small fraction of the total farmers land under conventional crops. Only thing is the acreage under GM crops had been increasing with time. Further, when it is said that European countries have accepted it does not mean that all countries in the European union have accepted the GM crops). There is no unambiguous and unanimous opinion about them. Hence their acceptability and cultivation varies widely across the globe. So a serious and convincing exercise with respect to all aspects without any confirmation bias needs to be taken to make them acceptable all over. Secondly the world should also realize that the farmers face several problems in agriculture either with conventional crops or genetically modified crops. Hence these issues also need to be addressed country wise. 
Consequences and Ethical Aspects of Different Medical Technologies

Surrogacy: Many are resorting to it. Even in case where there is no surrogacy but artificial insemination is used unethical practices are possible. Doctors try to set right the problem of premature abortions by hormonal treatment. While the treatment may be successful in delivering a child, the lady afterwards may suffer from health complications. Hospitals should ensure a normal delivery and should not be hasty to go for cesareans. Of course in some cases women opt for cesarean and avoid normal delivery. They should be informed that children so born can be of compromised immunity.

Recently a successful delivery of a baby has been reported by technology of Tri parental crossing. In this, Nuclear DNA comes from the original parents but mitochondrial DNA comes from another woman who is normal. This is done to protect the child mitochondrial inherited diseases. Since mitochondria are semi-autonomous organelles and heavily dependent on nucleus, the interactions between the nucleus and the transplanted mitochondria needs to be further investigated.

Pre-natal Diagnosis/ Amniocentesis/Abortion, Organ donation/donors, Research on Human cloning

Designer babies: How to decide it? To ban or not to ban? Presently situation varies across different places even for simple options like abortion which is otherwise a routine practice in many other places. Once religious leaders protested saying <<Man playing against God!>> A smart scientist replied. Revered Sirs, how can you say it is man playing against God? How we are able to do all these? How we will be able to do anything we want in future? Is it not because of the knowledge bestowed on us by the God ? Only to the extent God gives us the knowledge we will be able to do that.

Recently LGBTQ (Lesbian, Gays, Bisexuals, Transgenders and Queer) has been approved in different places and in future it may be approved in more number of places. Now with Bisexuals and Queers there may not be a problem of child bearing. Suppose Lesbians and Gays want to have children? Do we have the required technology? I am sure there will be future advances medical technology. Research to fulfill the ambitions of the above. Different situations can be visualized. Each Lesbian partner may want to have a child or the partners together want to have their child i.e. born to them. How can we make it possible? Each Lesbian partner may want a female or a male child. In these cases the lesbian has to go for a gamete donor accordingly and she can have the embryo implantation and bear the child. If the lesbian partners insist that they want a child born to them together? As they are females they have only X chromosomes and only female children can be thought of. How about Gays? They have both $\mathrm{X}$ and $\mathrm{Y}$ chromosomes.

Their desire also can be as above each partner wants to have a separate child or they may insist on having a child born only to them. In their cases as they have both $\mathrm{X}$ and $\mathrm{Y}$ chromosome they can opt for either male or female child. They may even give a preference as to which partner's $\mathrm{X}$ and which partner's $\mathrm{Y}$ they want to use! ? The techniques for the separation of $X$ and $Y$ chromosomes bearing sperms --sperm sorting- are available and need to be further improved. In any case they have to opt for a surrogate lady. As on today it is too much a fantasy to think of the development of a child starting from an embryo in an artificial environment. Even then a surrogate is required to breast feed the child. However even in all the above cases (and including the natural cases where a mother has died after giving birth to a child) a surrogate for breast feeding many did avoid and could still bring up the child on oral feeding. There is a need to do research in this aspect for the best development of the baby.

So one can imagine how many individuals may be involved in different situations in the final bringing up of the child. How about Transgenders? Should we not respect their emotional need to have a baby? How they can have? A theoretical possibility is remove the nucleus from the somatic cells of the Trans genders and implant in an embryo devoid of nucleus and with the help of the surrogate a baby can be delivered! The question is whether all the chromosomes in the somatic cells of the transgender are normal? If not is possible to edit them? It is quite possible that even with some abnormality the Trans genders may be happy to have a baby whom they can call as their own? Above all, can humans be cloned a choice even persons who are otherwise normal may prefer it? All this is fantasy or a future reality? In any case research needs to be done towards these goals--Science for Science Sake. It may or may not be a success-. Many researchers say many things will be possible in the future All these, is it ethical? Is it man playing against God? The answer for the last question is given above. Ethics can vary from country to country and in the same country from time to time.

With animal cloning-sheep, cows, frogs, mice etc- not much hue and cry is made as with the medical technologies involved in the production of a child. However there is a need to bother and do research in animal cloning too regarding their normal development, productivity, edible nature and life spans. In case of plants where through tissue culture millions of true to type plants are produced there is absolutely not ethical issues involved and it is rather sought after.

Of course nature itself has created vegetative propagation and identical twins. But bioethics and consequences concerned with medical technologies is a serious issue. In view of the above it cannot be over emphasized that adequate medical knowledge and advice and due economic compensation and medical insurance is required both for all those affected with the adoption of medical technologies old and emerging.

\section{Next Generation Genome Sequencing technologies (NGS)}

The demand for genome sequencing is growing heavily, along with the pressure of analyzing the same in much shorter times, 
economically, and greater accuracy..With the help of the Next Generation Sequencing technologies, the above is likely to be possible. We should take up projects on the sequencing of specific and medically interesting target groups like spastic children, whiz kids/child prodigies, congenital abnormalities etc. The DNA sequencing studies must be coupled with transcriptomics, proteomics and metabolomics in the above cases. A mention may be made about «nano pore sequencing technology». This technology can be fabricated as a portable device and can be used both in the lab and field to sequence genomes economically and in a short span of time. The technology finds applications in bio surveillance, clinical diagnosis and monitoring disease outbreak in the field. More data and improvements are required before the above technologies become a routine methodology.

\section{CRISPR-Cas9 Genome Editing Technology}

CRISPR-Cas9 is a targeted genome editing tool has a wide range of potential applications and the tool is still undergoing further improvements. The technique can be used to add, remove, and alter parts of the DNA sequence precisely in all broad categories of organisms. In humans the technique is used for treating several diseases. Though not genome editing in somatic cells editing in germ cells is a serious bioethical issue.

The tool has been studied in the model Plant Arabidopsis and has been exploited towards crop improvement in several crops Viz, tobacco, tomato, soybean, rice, wheat, maize, sorghum, citrus and poplar etc. The tool has been used and is being used to edit genes in different animals Viz; monkeys, mammoths, mosquitoes, pigs, goats, honeybees, chickens, fishes, ticks, aquatic snails, ferrets etc. The goals in the above cases were to prevent the transmission of vector born diseases and other diseases, protect the animals from infectious agents, produce drugs (farmaceuticals) and vaccines, provide for safe human consumption, preservation of endangered species, provide pets and aquariums, improving the working ability of dogs etc,. A related tool CRISPRi (CRISPR mediated interference) has been successfully used to target a large number of «large non-coding RNA's» (lnc RNA's) which are common in Human cells and play vital roles in many cellular processes. The technique would help in testing the functionality of various lnc RNA's.

Synthetic biology: There is an uncontrollable excitement in synthetic biology or making synthetic DNA of as much size as possible with the ultimate aim of synthetic life. Few examples are synthesis of 9.6 kilo base pair Hepatitis C virus genome, 7741 base poliovirus genome. After the human genome sequence the Craig Venter Institute has become very famous for synthetic biology. They synthesized 5386 bp genome of the bacteriophage Phi X 174; Mycoplasma laboratoriuma. Partially synthetic species of bacterium derived from the genome of Mycoplasma genitalium; the genome of the bacterium Mycoplasma mycoides and transplanted it into an existing cell of a Mycoplasma capricolum. Whose DNA was removed and the bacterium was viable. In 2016 J. Craig Venter Institute (JCVI) and Synthetic Genomics,
Inc. (SGI) beginning with Mycoplasma mycoides successfully designed and constructed the first minimal synthetic bacterial cell, termed JCVI-syn3.0. It functions with just contains 531,560 base pairs and 473 genes. In principle this potential may be used for chemically synthesizing viruses for biological warfare.

\section{Nano biotechnology}

The field of nano biotechnology: The term being interchangeably used with bio nano technology and nano biology is one of the recently emerged technologies with potential applications particularly in humans. Among the metals nano particles of silver, gold, copper, platinum, palladium. Iron, zinc and titanium have received more attention. Particularly silver and gold nano particles are more widely used -written as Ag NP and Au NP respectively. While material scientists prepare the nano particles by physical and chemical methods, biological scientists prepare nano particles making use of different plant and different microbial extracts and term it as Green Chemistry. Nano particles so prepared are used for human therapeutic applications. They can be/have been used as anti microbial, antioxidant and anticancer agents with or without targeted drug delivery. Nano particles have also been exploited to kill larvae of mosquitoes causing malaria, dengue and filariasis. However the degree of success need to be improved a lot. Adequate amount of experiments need to be conducted with due controls, that is using standard drugs as controls, using nano particles with and without targeted drug delivery using nano particles prepared by physical and chemical methods and biological methods, and also studying the mode of action of nano particles in causing the effect. Presently it is difficult to claim and explain much. A Nano particle also seems to have growth promoting effects on different plants and is reflected by increase in the amount of different desirable biochemical parameter.

\section{Stem Cells Technology}

Stem cells transplantation is commonly used to treat a variety of blood and bone marrow diseases, blood cancers, and immune disorders. In stem cell therapy Bone marrow transplant is more commonly used than stem cells derived from umbilical cord blood. Stem cells, can differentiate into desired cell types, and can be used as a replacement and there by treat diseases like Parkinson's, stroke, heart disease and diabetes. It is one of the mysteries of nature as to how a complete body develops from a zygote. Research on Human embryonic stem cells can help to understand how a complete body develops from a fertilized egg. However this has become a serious bioethics issue. Many infertile couples go to in vitro fertility centers. Unused embryos have to be destroyed and should not be used for research purposes without the consent of the donor couples and they need to be duly informed.

Either the unused embryos may be used for others or research carried out on Embryonic Stem Cells developed from the embryos after in vitro fertilization. While so much has been discussed on this technology a latest breakthrough in their 
application is in the resurrection of Brain dead patients. Bio quark, a biotech company based in the United States, has been permitted to implant stem cells in the brain-dead patients with the ultimate hope of stimulating and regrow neurons and make them alive again! The implantation of stem cells is complimented with other techniques involving the treatment of spinal cord and nervous stimulation. Presently it is defined as a long term goal. At any time if it is successful it is a great human achievement. After the discovery of the atom/ atomic structure it did not take much time to develop an atomic bomb! So who knows how science develops in future?

Bioterrorism: It refers to the intentional release of biological agents like bacteria, viruses, fungi or toxins for destruction of humans, animals and plants. They may either die or suffer from severe disease and die gradually without any form of treatment available and in the process can spread the disease among the population. Techniques of microbial culture, mutagenesis, genome editing and synthetic biology may lead to the large scale development of new and more lethal biological agents either from those already existing in nature or afresh. Fear exists as they can be easily and secretively carried to the place of their release. Considerable thought is there on the delivery options of these harmful agents. They may be released into the atmosphere or into water bodies or food material. Since the effect of the organism can spread to distant places of a strategies for targeted deliveries have to be researched. While many organisms are listed as potential agents for Bioterrorism, a greater probability seems to be visualized for viral organisms like small pox, Ebola, and bacterial diseases like plague, botulism, and anthrax. An important point to be noted is that any research into this area beyond a certain extent will be a secret. Till the act of Bioterrorism is perpetrated one may not know about the agent and the modus operandi. As a precautionary measure soldiers can be equipped with medicines and get prior vaccination for the possible attacks. However it is difficult for the general public or their animal and plant assets. In view of the above description other terms which are in use are biological warfare, germ warfare, bio weapons etc.

\section{Microbial and Genomics/ Metagenomics/Microbiome (Second Human Genome)}

Human body both outside and inside has trillions of microorganisms. They include, bacteria (both eubacteria and archae bacteria) fungi, viruses and protists. The genomes of all microorganisms on and within the human body are referred to as micro biome. Micro biome is immensely beneficial to the human body and they are involved in several important processes Viz; regulating appetite, immune system, obesity, brain development and emotions, aiding in digestion and wound healing and protection from diseases. Our digestive tract-small and large intestines-put together constitute nearly $99 \%$ of the total microorganism. They are referred to as gut microbiota or gut flora and are essential for our overall well being in view of the above mentioned roles. Hence the is referred to as second human genome project. The soil micro flora has lot of agricultural and environmental importance besides them being of potential benefit industrially.

In nature vast majority of microorganisms are unculturable. The percentage of unculturable microorganisms varies with the specific niche, for example, soil, gut flora, micro flora in different parts of the human body etc.. The problem of unculturability researchers have tried and trying to overcome by resorting to Metagenomics. By this approach also researchers have identified new phyla, genera and species and useful genes. However researches on making the presently unculturable organisms culturable should not be given less importance rather should be strengthened. It is a very challenging and is an enormous amount of work as vast majority of organisms is unculturable. Of course some success has been reported with some microorganisms. In some cases the organisms form spores to survive outside their natural environment. Hence further research attempts should be made to revert it back.

Spore formation and reverting back is a form of differentiation and dedifferentiation and this process must be thoroughly investigated. Though thousands of metagenomic data is there we do not have the complete genome sequence data for a vast number of micro organisms as they are unculturable. Scientists have really done a commendable job of sequencing nearly 30,000 microbial genomes (NCBI, 2014; Now the number may be more). However even this number is much less as compared to the total microbial diversity available in nature. With the NGS technologies hopefully we can make an exponential progress in case we can standardize conditions for the culture of hitherto unculturable microorganisms.

\section{Bioremediation and Recycling of Plant Biomass}

There are so many contaminated environments harboring various categories of pollutants emanating from various sources, to varying concentrations causing serious problems. For example drinking water contamination, irrigation water and soil contamination affecting agriculture, contamination of other water bodies like lakes, rivers and even oceans. Pollutants are referred to as Xenobiotics. Complete bioremediation of these xenobiotics and complete restoration of the original environment is still a long term yet rewarding research goal. Further in case we can make the organisms to completely utilize the xenobiotics as a source of carbon, energy etc and make useful products, it is a highly rewarding goal with the double advantage of removing the xenobiotics and also getting useful products. All categories of microorganisms must be exploited in this regard -eubacteria, fungi, archae bacteria, and other extremophiles.

While considerable success has been there in recycling cellulose towards useful products, it is not so with the other two major components of Biomass, Lignin and Hemi cellulose. Research needs to be carried out to explore microorganisms- 
either naturally occurring or genetically engineered - which can effectively utilize lignin and hemi cellulose and convert them to useful products. Lignin is the most abundant aromatic polymer on earth and thus is available in plenty. Knowledge of the genome sequences and the metabolism of various organisms mentioned above can help in metabolic engineering of the organisms towards the above mentioned desired goals.

\section{References}

1. Adhikarla S Rao (2016) Conversion of C-3 plants into C-4 plants may lower the Rubisco amounts with negative effects on grain yield and protein concentration. Journal of Plant Biochemistry and Biotechnology 25(4): 337-338.

2. http://www.gmo-compass.org/.

3. http://www.fooddive.com/news/genetically-engineered-potatovarieties-approved-by-us/437206/

4. https://www.newscientist.com/article/dn28283-more-than-half-ofeuropean-union-votes-to-ban-growing-gm-crops/

5. http://www.ecowatch.com/its-official-19-european-countries-sayno-to-gmos-1882106434.html

6. www.livescience.com/32083-cloning-people-biology.html

7. http://www.sciencemag.org/news/2016/09/unanswered-questionssurround-baby-born-three-parents

8. http://americanpregnancy.org/infertility/in-vitro-fertilization/

9. http://www.webmd.com/infertility-and-reproduction/guide/usingsurrogate-mother\# 1

10. https://gaycenter.org/about

11. Sahar Baheri, Ghasem Saki, Javad Mohammadi Asl, Ali Khodadadi (2016) Assessment of the Separation of X- and Y-Chromosome Bearing Sperms of Fertile Men by Albumin Gradients Using Real Time PCR Jentashapir J Health Res 7(2): e31079.

12. https://www.ebi.ac.uk/training/online/course/ebi-next-generationsequencing-practical-course/what-you-will-learn/what-nextgeneration-dna-pdf.

13. https://www.illumina.com/content/dam/illumina-marketing/ documents/products/illumina_sequencing_introduction.pdf

14. Elizabeth Pennisi (2016) Genome sequencing in the hand and the bush. 23 Dec Science (USA) 354(6319): 1518-1523.

15. Gaoyuan Song (2016) CRISPR/Cas9: A powerful tool for crop genome editing. The Crop Journal 4(2): P75-P82.

16. Fangyuan Wang Lei S Qi (2016) Applications of CRISPR Genome Engineering in Cell Biology. Trends in Cell Biology 26(11): 875-888.

17. Sara Reardon 09 March 2016, Welcome to the CRISPR zoo Birds and bees are just the beginning for a burgeoning technology. Nature 531(7593): 160-163.

18. Lin SJ, Horlbeck MA, Cho SW, Birk HS, Malatesta M, et al. (2017) CRISPRi based genome scale identification of non-coding RNA loci in human cells. Science 355(6320): 39.

19. Ewen Callaway (2016) 'Minimal' cell raises stakes in race to harness synthetic life'. Craig Venter's creation comes as CRISPR gene-editing methods provide alternative ways to tinker with life's building blocks. Nature 531(7596): 557-558.

20. https://www.sciencenews.org/article/scientists-build-minimumgenome-bacterium

21. Ahmad M, Alsalhi MS, Siddiqui, MK (2010) Silver nano particle applications and human health. Clinica chimica acta 411(23-24): 1841-1848.

22. Raj Kuberan C (2015) Synthesis and characterization of silver nano particles from the latex of Calotropis giagantea (L.) W.P. AATTON, Euphorbia antiquorum and Carica papaya and their biological evaluation. PhD (Biotechnology) Thesis submitted to Bharathidasan University, Tiruchirappalli-620024, Tamil Nadu, India

23. http://themindunleashed.com/2017/03/scientists-get-green-lightresurrect-dead-stem-cells.html

24. http://www.eurostemcell.org/embryonic-stem-cells-where-do-theycome-and-what-can-they-do

25. http://www.emedicinehealth.com/biological_warfare/article_em.htm

26. http://www.medicinenet.com/bioterrorism/article.htm

27. Sahar Baheri, Ghasem Saki, Javad Mohammadi Asl, Ali Khodadadi (2016) Assessment of the Separation of X-and Y-Chromosome Bearing Sperms of Fertile Men by Albumin Gradients Using Real Time PCR. Jentashapir J Health Res 7(2): e31079.

28. Sharpton TJ (2014) An introduction to the analysis of shotgun metagenomic data Front Plant Sci 5: 209.

29. http://www.microbiologytext.com/5th_ed/news/display/2013/8/2/ the-unculturables/

30. Franck Stefani OP (2015) Culture-Dependent and -Independent Methods Capture Different Microbial Community Fractions in Hydrocarbon-Contaminated Soils. PLoS One 10(6): e0128272.

31. Alejandra Escobar-Zepeda, Arturo Vera-Ponce de León, Alejandro Sanchez-Flores (2015) The Road to Metagenomics: From Microbiology to DNA Sequencing Technologies and Bioinformatics. Front. Genet 6: 348.

32. Browne HP, Forster SC, Anonye BO, Kumar N, Neville BA, et al. (2016) Culturing of 'unculturable' human microbiota reveals novel taxa and extensive sporulation. Nature 533(7604): 543-546.

33. Joseph Nesm (2016) Back to the Future of Soil Metagenomics. Front Microbiol 7: 73 .

34. Miriam Land, Hauser L, Jun SR, Nookaew I, Leuze MR, et al. (2015) Insights from 20 years of bacterial genome sequencing. Funct Integr Genomics 15(2): 141-161.

35. Pabulo Henrique Rampelotto (2013) Extremophiles and Extreme Environments. Life (Basel) 3(3): 482-485.

36. Enshaeieh M, Abdoli A, Madani M, Bayat M (2015) Recycling of lignocellulosic waste materials to produce high-value products: single cell oil and xylitol. International Journal of Environmental Science and Technology 12 (3): 837-846.

37.Zahid Anwar, Muhammad Gulfraz, Muhammad Irshad (2014) Agroindustrial lignocellulosic biomass a key to unlock the future bioenergy: A brief review 7(2): 163-173. 
This work is licensed under Creative Commons Attribution 4.0 Licens

DOI: 10.19080/AIBM.2017.03.555613
Your next submission with Juniper Publishers will reach you the below assets

- Quality Editorial service

- Swift Peer Review

- Reprints availability

- E-prints Service

- Manuscript Podcast for convenient understanding

- Global attainment for your research

- Manuscript accessibility in different formats ( Pdf, E-pub, Full Text, Audio)

- Unceasing customer service

Track the below URL for one-step submission https://juniperpublishers.com/online-submission.php 